\title{
Intra-Firm Inventory Management Model with Transshipments
}

\author{
Biri Anthony, Degbe Sewodo Augustin \\ College of Transport and Communications, Shanghai Maritime University, Shanghai, China \\ Email: Bonto2day@yahoo.com, deseaucom@yahoo.com
}

How to cite this paper: Anthony, B. and Augustin, D.S. (2017) Intra-Firm Inventory Management Model with Transshipments. American Journal of Industrial and Business Management, 7, 15-26. http://dx.doi.org/10.4236/ajibm.2017.71002

Received: December 14, 2016

Accepted: January 7, 2017

Published: January 10, 2017

Copyright $\odot 2017$ by authors and Scientific Research Publishing Inc. This work is licensed under the Creative Commons Attribution International License (CC BY 4.0).

http://creativecommons.org/licenses/by/4.0/

\begin{abstract}
This paper analyzes the implementation of transshipments among two independent locations which belong to one parent firm and the impact of transshipments, when implemented between these two locations. We examine how the possibility of such transshipments affects the optimal inventory orders at each location and find that, if each location aims to maximize its own profit, their inventory choices will not in general maximize joint profits. However, we find transshipment prices which if implemented by the parent firm as incentive design will make each location behave in order to optimize aggregate profit.
\end{abstract}

\section{Keywords}

Inventory Management, Transshipments, Newsvendor Model

\section{Introduction}

Inventory management is a critical aspect of enterprise-wide optimization. Inventories are used in production and logistics networks to coordinate supply cycles and to mitigate the risk associated with uncertainty. The importance of inventory in industrial applications derives from the effect of stockouts in the levels of customer satisfaction and the impact of stock out in the economic balance of companies.

Remarkably, the value of U.S inventories was estimated to be over $\$ 1707$ billion in December 2013 [1], and the opportunity cost ascribed to capital invested in inventories added up to $\$ 434$ billion in 2012 [2]. Therefore, the potential savings from stockout prevention and inventory related cost offer a huge opportunity for optimization.

Inventory plays a variety of roles. It can be used to buffer tempered mismatches between supply availability, processing rates, and demand in integrated 
production networks. It is also useful to satisfy safety requirements, in cases where the availability of hazardous raw materials can be replaced with inventory of its products.

Inventory also plays an important role in the coordination of maintenance turnaround between various facilities across a site. In general, the benefits of inventories derive from their ability to reduce the interdependence of processing units, to mitigate the effects of bottlenecks, and to facilitate capacity utilization.

Many inventory management strategies have been proposed since Harris introduced the Economic Order Quantity (EOQ) model in 1913. Before the 1930s, merchants used the skills of experience and intuition in their shop keeping writing down purchases or looking at how many units were gone at the end of the day and then do their best to forecast for the future needs. However, efficiency and mass production became the main objectives of business after the industrial revolution, along with an improved customer experience at the point of sale.

In the 1960s, the affordable laser technology which allowed for smaller, faster and cheaper readers or scanners as well as the Universal Product Code (UPC) was developed. These systems boosted the efficiency of the computing power which helped in trading and managing inventories better.

In recent years, more flexible inventory systems also allow lateral transshipments within an echelon, thus, between wholesalers or retailers [3]. In this way, members of the same echelon pool their inventories, which can allow them to lower inventory levels and cost whilst still achieving the required service levels.

As a risk-pooling strategy, transshipment provides an efficient and effective approach for firms to reduce inventory carrying costs without negative effects on customer service. For example, Saturn has achieved impressive success with aftersales service through the practice of sharing automobile parts among its dealers [4]. When one dealer is out of a particular Stock Keeping Unit (SKU), this dealer will first contact a nearby Saturn dealer to see if the SKU is available there. If the part is available, transshipments are implemented from the location with excess stock to the location with insufficient supply. Through transshipments, a dealer can quickly receive the part needed and thus satisfy customer requests for either maintenance or repair faster than if the part were backordered from the original supplier or the central distribution center.

The study of multi-location models with transshipment is an important contribution for mathematical inventory theory as well as for inventory practice. The idea of lateral transshipments is not new. The first study dates back to the sixties, the two-location-one-period case with linear cost functions was considered by Aggarwal [5].

Krishnan [6] studies with N-location-one-period model, where the cost parameters are the same for all locations. Johnson [7] incorporated non-negligible replenishment lead times and transshipment lead times among stocking locations to the multi-location model.

The effect of lateral transshipment on the service levels in a two-locationone-period model was studies by Tagaras [8]. In all works only minimization of 
the expected total cost is considered.

Our major contribution is to determine the demand variations facing the two locations under which a transshipment policy is likely to increase performance of the parent firm. In particular, we examine how the variance in demand affects inventory levels, revenues and profits of the firm.

This paper is organized as follows. The next section provides a review of literature on inventory management and transshipments. Section 3 sets up the basic framework that allows transshipment between two locations. We look at the classic newsvendor problem as a special case within this framework. Section 4 examines how the possibility of transshipments between these locations affects inventory orders in the case where they are centrally determined by the parent firm. To illustrate the model, we give a numerical analysis in this for normal distribution and compare to the corresponding results of the classical newsvendor model and finally, Section 5 presents the conclusions and future research.

\section{Literature Review}

\subsection{Inventory Management}

Inventory can be described as the stock of any item or resource that is used in an organization [9]. There are many reasons for an organization to hold inventory, but a few main reasons are identified by Simchi-Levi [10]. Firstly, to provide for unexpected changes in customer demand; again, to function as a buffer that caters for the presence of uncertainty in some situations; also, to ensure stock availability during supply lead times and finally, to achieve economies of scale offered by transportation companies.

Inventory management under uncertainty originated in the 1950s and the first significant contribution to this field was provided in 1951 by Arrow [11] in which they present a dynamic inventory model with random demand described by a known probability distribution. Their model is commonly referred to as the $(\mathrm{s}, \mathrm{S})$ or min max inventory management approach and can be seen as an adaptation of the original Economic Order Quantity (EOQ) model [2] to enable the incorporation of erratic or lumpy demand patterns [12].

The work of Arrow et al. [11] was then extended by Dvoretzky [13] [14] in two comprehensive papers. Similar to Arrow et al. [11], their first paper focuses on an inventory model where demand is represented by a random variable following a known probability distribution [13]. Their second paper deals with inventory models with uncertain demand and unknown distribution [14].

Since then, many papers on inventory management and modeling under uncertainty have been published as seen in Chu [15]; Handfield [16]; Maiti [17]; Mandal [18]; Ryu [19]; Solyali [20].

A technique often used in the literature to deal with the complexity of inventory management and modeling under uncertainty is to assume that the uncertain parameter, for instance demand, is random and that its probability distribution is known with certainty. In such cases, stochastic programming can be used to incorporate uncertainty into the model. Similar examples may be found in 
Maiti et al. [17], Ryu et al. [19].

\subsection{Transshipments}

In the field of supply chain management, one of the most important components is meeting customer demand in an effective and efficient manner. Although, there are a number of possible solutions, transshipment is among the most practical approach.

Lateral transshipments within an inventory system are stock movements between locations of the same echelon [3]. There are two main streams of research on lateral transshipment: one is to minimize the total expected cost; lateral transshipments are arranged among all of the stocking locations before customer demands are realized, and two, lateral transshipments are made to meet unsatisfied customers when one of the stocking locations is out of stock and another has extra stock on hand.

In the periodic review system, Krishnan et al. [6] may be the first to provide the fundamental framework for a single-period-two-location problem. They analyze transshipment in a setting with a multi-location distribution network that consists of a number of warehouses, characterized by centralized control, independent demand and identical inventory holding and shortage cost for all locations. Their analysis further suggests that, under these conditions, transshipments equalize optimal inventory and service levels throughout stocking locations.

Building on Krishnan et al. [6], Tagaras [8] investigates the effect of transshipments on customer service levels, measured by non-stockout probability and fill rate. Tagaras [8] finds that, the complete pooling policy improves the service level in a two-location distribution system and that, the service levels at both locations will be equalized through transshipments under the conditions that the locations have identical market demands and inventory cost structures.

Robinson [21] considers a multi-period, multi-location problem, derives the optimal ordering policy and finds analytical solutions for the two-location case. $\mathrm{Hu}$ [22] studies a multiple period setting but focus on the two-location transshipment problem. Zhao [23] studies the dynamic transshipment policies for a multi-location problem. In a recent paper, Heide [24] studies the transshipment of books with online demand to minimize the logistic costs in the library system.

Other recent related transshipment studies can be found in the work of $\mathrm{Yu}$, Tang and Niederloff [25]; Jiang and Anupindi [26], Zhao and Atkins [27], Shen, $\mathrm{Hu}$ and Liao [28].

\section{The Problem Description and Modeling}

Our basic framework follows closely the work of Krishnan et al. [6]. We consider one parent firm with two branches serving customers at two distinct locations noted as $i$ and $j$ throughout the paper. Firm $i$ procures inventory $Q_{i}$ from a central supplier at a fixed unit cost $w_{i}$. When placing the orders, the firms do not know the level of demand, $D_{i}$, that will be realized at both loca- 
tions, however, the joint distribution over demand realizations $\left(D_{1} \times D_{2}\right)$ is known. For simple and straightforward analysis, we assume the probability distribution to be twice differentiable and strictly increasing on its support.

Firm $i$ obtains revenue $y_{i}$ for every unit sold and if it cannot meet the entire demand, it is penalized $P_{i}$ for every unit of unmet demand. Unsold stock has a salvage value, $S_{i}$ and we also define the marginal value of additional sales at location $i$ as $M_{i}=y_{i}+P_{i}$.

Table 1 provides the summary of the notations used in this study.

From Table 1, let $C_{i j}$ be the price charged by location $i$ for each unit transshipped to location $j$. We also assume that, $t_{i j}$ is the cost incurred by location $i$ for every unit it transship to location $j$. Therefore, location $i$ enjoys a surplus of $C_{i j}-t_{i j}$ for each unit transshipped and would find it profitable to transship to $j$ whenever this surplus is greater than the salvage value, $s_{i}$; location $j$ would also find it profitable to accept transshipments whenever it is stocked out and the transshipment price is less than the marginal value of additional sales.

According to the complete pooling assumptions defined by Tagaras [8], transshipments from location $i$ to location $j$ are mutually profitable whenever there is excess demand at location $j$ and surplus stock at location $i$ and $C_{i j} \in\left[s_{i}+t_{i j}, M_{j}\right]$. We further assume that, $s_{i}+t_{i j}<M_{j}$ for $i, j=1,2$. Again, we assume that, $w_{i}<w_{j}+t_{j i}, s_{i}<s_{j}+t_{j i}$, and $M_{i}<M_{j}+t_{j i}$. These restrictions ensure that it is not beneficial to always buy through another location and that transshipment occurs only when there is surplus stock at one location and simultaneously excess demand at the other location.

Table 1. Notation description used in the model.

\begin{tabular}{|c|c|}
\hline Notation & Description \\
\hline \multirow[b]{2}{*}{$y_{i}, y_{j}$} & Unit price of goods sold by \\
\hline & Location $i$ and $j$ respectively \\
\hline$w_{i}, w_{j}$ & Procurement cost paid by Location $i$ and $j$ \\
\hline$H_{c}$ & Average inventory carrying/holding cost \\
\hline$S_{i}, S_{j}$ & Salvage value for each unit of unsold stock \\
\hline$p_{i}, p_{j}$ & Penalty cost for each unit of unmet demand \\
\hline$t_{i j}, t_{j i}$ & $\begin{array}{l}\text { Cost incurred in transshipping a unit from Location } i \text { and } j \\
\text { and vice versa }\end{array}$ \\
\hline$C_{i j}, C_{j i}$ & Transshipment price charged by $i$ to $j$ and by $j$ to $i$ \\
\hline$Q_{i}, Q_{j}$ & Optimal inventory levels for $i$ and $j$ respectively \\
\hline$X_{i j}, X_{j i}$ & Quantity of transshipments from $i$ to $j$ and from $j$ to $i$ \\
\hline$R_{i}, R_{j}$ & Actual sales in unit by $i$ and $j$ \\
\hline$U_{i}, U_{j}$ & Amount of unsold stock at $i$ and $j$ respectively \\
\hline$Z_{i}, Z_{j}$ & Amount of unmet demand of $i$ and $j$ \\
\hline$D_{i}, D_{j}$ & Level of demand at locations $i$ and $j$ respectively \\
\hline
\end{tabular}

Source: Li Zou [29]. 
Following the constraints above, we define the transshipment quantity from location $i$ to location $j$ as: $X_{i j}=\min \left[\left(D_{j}-Q_{j}\right)^{+},\left(Q_{i}-D_{i}\right)^{+}\right]$, where $x^{+}=\max (x, 0)$. In this expression, the $\left(D_{j}-Q_{j}\right)^{+}$represents excess demand at location $j$ while surplus stock at location $i$ is represented by $\left(Q_{i}-D_{i}\right)^{+}$.

The transshipment level takes the lower value between the overstock at one location and the under stock at the other location. Transshipment level from location $j$ to location $i$ can similarly be written as:

$$
X_{j i}=\min \left[\left(Q_{j}-D_{j}\right)^{+},\left(D_{i}-Q_{i}\right)^{+}\right] .
$$

Given the transshipment quantity above, sales for location $i$ can be written as $R_{i}=\min \left(D_{i}, Q_{i}\right)+X_{j i}$ units while unsold stock at location $i$ is $U_{i}=\left(Q_{i}-D_{i}-X_{i j}\right)^{+}$and unmet demand is $Z_{i}=\left(D_{i}-Q_{i}-X_{i j}\right)^{+}$.

Similarly, the same expressions can be written for location $j$ as follows:

$$
R_{j}=\min \left(D_{j}, Q_{j}\right)+X_{i j} ; U_{j}=\left(Q_{j}-D_{j}-X_{j i}\right)^{+} ; Z_{j}=\left(D_{j}-Q_{j}-X_{i j}\right)^{+}
$$

The expressions above depend on $D_{i}, D_{j}, Q_{i}$ and $Q_{j}$; therefore, expected profit at locationi will be:

$$
e_{i}\left(Q_{i}, Q_{j}\right)=E\left[y_{i} R_{i}+\left(C_{i j}-t_{i j}\right) X_{i j}-C_{j i} X_{j i}+s_{i} U_{i}-p_{i} Z_{i}\right]-w_{i} Q_{i}
$$

Next, we develop a classic newsvendor problem using equation (a) above. This newsvendor has no transshipments but provides very useful benchmark. By setting $X_{i j}=X_{j i}=0$ and eliminating the subscripts, we get the expected profit for the newsvendor as:

$$
\begin{aligned}
\mathrm{e}^{n}(Q) & =E[y R+s U-p Z]-w Q \\
& =E\left[y \min (D, Q)+s(Q-D)^{+}-p(D-Q)^{+}\right]-w Q
\end{aligned}
$$

Let the probability of stockouts be denoted by $\operatorname{Prob}(D>Q)$, the marginal profitability of increasing the stock level is given by:

$$
\frac{\delta \mathrm{e}^{n}}{\delta Q}=y \operatorname{Prob}(D>Q)+s \operatorname{Prob}(D<Q)+p \operatorname{Prob}(D>Q)-w
$$

The optimal inventory choice trades off the expected marginal benefit with its marginal cost, $w$. There exists a unique order quantity $Q^{n}$ that maximizes the newsvendor's profit if the distribution over demand is continuous and strictly increasing. Setting Equation (c) to zero and rearranging, we arrive at a similar solution for the newsvendor problem:

$$
\operatorname{Prob}(D<Q)=\left(\frac{M-w}{M-s}\right)
$$

The expected total profits for the two locations will therefore be:

$$
\begin{aligned}
\mathrm{e}^{t}\left(Q_{1}, Q_{2}\right)= & E\left[y_{1} R_{1}+y_{2} R_{2}-t_{21} X_{21}-t_{12} X_{12}+s_{1} U_{1}+s_{2} U_{2}-p_{1} Z_{1}-p_{2} Z_{2}\right] \\
& -w_{1} Q_{1}-w_{2} Q_{2}
\end{aligned}
$$

Next, we calculate the derivative of expression (e) above to obtain the marginal unit of inventory at location $i$ as follows: 


$$
\begin{aligned}
\frac{\delta \mathrm{e}^{t}}{\delta Q_{i}}= & \left(y_{i}+p_{i}\right) \operatorname{Prob}\left(D_{i}>Q_{i}+\left(Q_{j}-D_{j}\right)^{+}\right) \\
& +\left(y_{j}+p_{j}\right) \operatorname{Prob}\left(D_{j}>Q_{j}+Q_{i}-D_{i}, Q_{i}>D_{i}\right) \\
& +t_{j i} \operatorname{Prob}\left(Q_{i}<D_{i}<Q_{i}+Q_{j}-D_{j}\right)-t_{i j} \operatorname{Prob}\left(Q_{i}+Q_{j}-D_{j}<D_{i}<Q_{i}\right) \\
& +s_{i} \operatorname{Prob}\left(Q_{i}>D_{i}+\left(D_{j}-Q_{j}\right)^{+}\right)+s_{j} \operatorname{Prob}\left(Q_{j}>D_{j}+D_{i}-Q_{i}, D_{i}>Q_{i}\right)-w_{i}
\end{aligned}
$$

Collecting terms, we have:

$$
\begin{aligned}
\frac{\delta \mathrm{e}^{t}}{\delta Q_{i}}= & M_{i}\left(1-\operatorname{Prob}\left(D_{i}<Q_{i}\right)-\operatorname{Prob}\left(Q_{i}<D_{i}<Q_{i}+Q_{j}-D_{j}\right)\right) \\
& +\left(t_{j i}+s_{j}\right) \operatorname{Prob}\left(Q_{i}<D_{i}<Q_{i}+Q_{j}-D_{j}\right) \\
& +\left(M_{j}-t_{i j}\right) \operatorname{Prob}\left(Q_{j}+Q_{i}-D_{j}<D_{i}<Q_{i}\right) \\
& +s_{i}\left(\operatorname{Prob}\left(D_{i}<Q_{i}\right)-\operatorname{Prob}\left(Q_{i}+Q_{j}-D_{j}<D_{i}<Q_{i}\right)\right)-w_{i}
\end{aligned}
$$

Expression (f) above has three components:

1) The additional inventory at location $i$ will result in incremental sales at location $i$ which will yield $M_{i}$ per unit except when there is surplus inventory at location $i$ or the effective excess supply at location $j$ could have enabled transshipments from $j$ to $i$. In this case, the marginal unit of $Q_{i}$ is $t_{j i}+s_{j}$.

2) If there is no stockout at location $i$ but demand exceeds effective supply at location $j$, the marginal unit can be transshipped to $j$, which will yield $M_{j}-t_{i j}$.

3) If demand at location $j$ does not exceed effective supply, and there is no stockout at $i$, the marginal unit is worth only its salvage value $s_{i}$. We can subtract the marginal procurement cost $w_{i}$ from the above to get the net marginal benefit.

Figure 1 shows six (6) possible events that may arise with transshipments. Descriptions of the events are as follows:

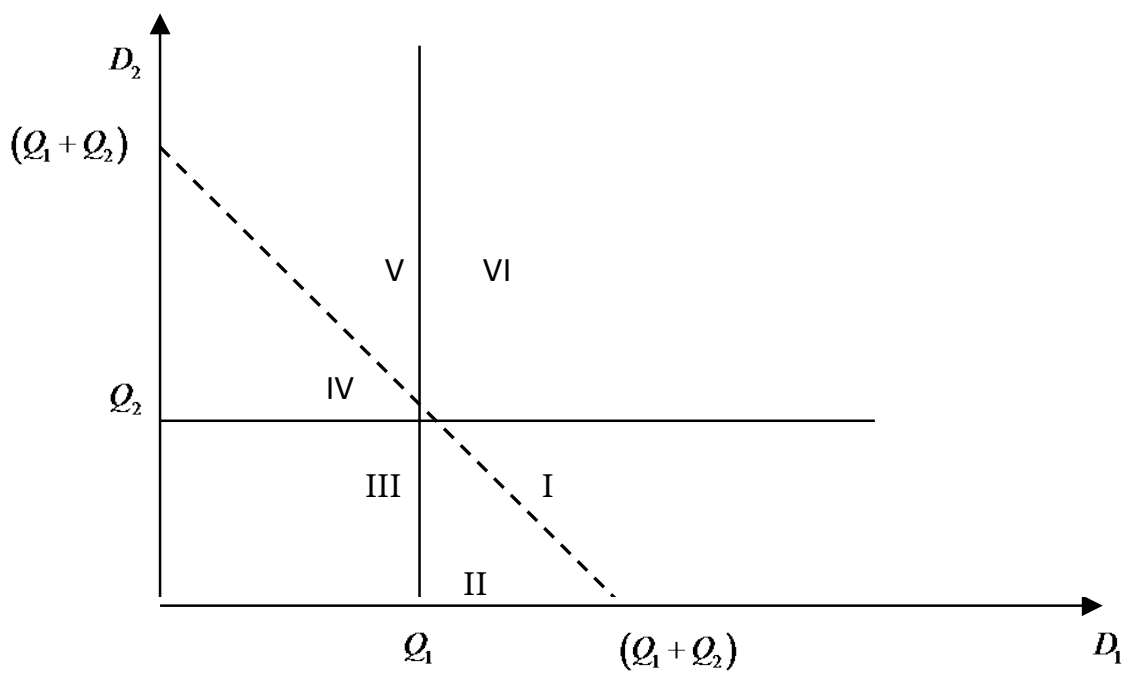

Figure 1. Six (6) possible events with transshipments. 
Event I

In this event, location $i$ has demand $D_{1}$, which is greater than the stock quantity $Q_{1}$; whereas location $j$ has demand $D_{2}$ less than its stock quantity $Q_{2}$. This event is parallel to event V.

Event II

Location $i$ is out of stock whereas location $j$ is overstocked. This event is parallel to event IV.

Event III

Both location $i$ and $j$ are overstocked in this event and therefore, no transshipments occur in this event.

Event IV

Location $j$ is out of stock, whereas location $i$ is overstocked and the joint stock quantities for both Location $i$ and $j$ is more than the aggregate demand at the two locations.

Event V

In this event, Location $j$ has demand $D_{2}$, which is greater than its stock quantity $Q_{2}$, whereas Location $i$ has demand $D_{1}$ less than its stock quantity $Q_{1}$. Hence, Location $i$ has a surplus stock $\left(Q_{1}-D_{1}\right)$ and Location $j$ is out of stock by the amount $\left(D_{2}-Q_{2}\right)$. Also, in this event, the total demand of Location $i$ and $j$ denoted as $\left(D_{1}+D_{2}\right)$, is greater than their aggregate stock $\left(Q_{1}+Q_{2}\right)$.

Event VI

Both Location $i$ and $j$ are out of stock in this event and no transshipments occur.

The probability functions of the various events are given in Table 2.

The work of Robinson [21] shows that, the expected profit function is concave in $\left(Q_{1}, Q_{2}\right)$, so the first-order conditions are sufficient for optimality.

Rearranging expression $(f)$, the conditions characterizing the optimal inventory order are:

$$
\alpha_{i}\left(Q_{i}\right)-\beta_{i}\left(Q_{i}, Q_{j}\right)\left(\frac{M_{j}-s_{i}-t_{i j}}{M_{i}-s_{i}}\right)+\gamma_{i}\left(Q_{i}, Q_{j}\right)\left(\frac{M_{i}-s_{j}-t_{j i}}{M_{i}-s_{i}}\right)=\left(\frac{M_{i}-w_{i}}{M_{i}-s_{i}}\right)(\mathrm{g})
$$

Table 2. Events and associated probability functions.

\begin{tabular}{clccc}
\hline Event & \multicolumn{1}{c}{ Description } & Probability & Notation & Transshipments \\
\hline III & $\begin{array}{l}\text { Both ations } i \text { and } j \text { are } \\
\text { over stocked }\end{array}$ & $D_{i}<Q_{i}$ & $\alpha_{i}\left(Q_{i}\right)$ & $X_{j i}=0$ \\
V $\quad \begin{array}{l}\text { Location } j \text { is out of stock } \\
\text { and Location } i \text { transships } \\
\text { all of its excess stock to } j\end{array}$ & $Q_{i}+Q_{j}-D_{j}<D_{i}<Q_{i}$ & $\beta_{i}\left(Q_{i}, Q_{j}\right)$ & $X_{j i}=0, X_{j i}=Q_{i}-I$ \\
II $\quad \begin{array}{l}\text { Location } i \text { is out of stock } \\
\text { and Location } j \\
\text { transships some of its } \\
\text { surplus stock to } i\end{array}$ & $Q_{i}<D_{i}<Q_{i}+Q_{j}-D_{i}$ & $\gamma_{i}\left(Q_{i}, Q_{j}\right)$ & $X_{j i}=D_{i}-Q_{i}, X_{i j}=$ । \\
\hline
\end{tabular}

Source: Li Zou [29]. 
The right-hand side of Equation ( $\mathrm{g}$ ) above is the adjustment of the newsvendor solution. The left-hand side adjusts $Q_{i}$ up due to the possibility of transshipment from location $i$ to $j$; and the third on the left-hand side adjusts $Q_{i}$ down due to the possibility of transshipments from location $j$ to $i$.

Next, we continue to calculate the transshipment prices and we ask the following question: does there exist a pair of transshipment prices that maximizes the total profit? If yes, then this can be implemented in many practical situations by the parent firm as incentive design to make each location behave in order to optimize aggregate profit.

There exist a unique set of transshipment prices $C_{i j}$ for $i, j=1,2$ that yields the joint optimal solution given by:

$$
C_{i j}^{*}=\left(\frac{M_{j} \beta_{i} \beta_{j}+\left(s_{j}+t_{j i}-M_{i}\right) \beta_{j} \gamma_{i}-\left(s_{i}+t_{i j}\right) \gamma_{i} \gamma_{j}}{\beta_{i} \beta_{j}-\gamma_{i} \gamma_{j}}\right)
$$

It is sufficient to look for transshipment prices which induce the locations to choose optimal order quantities.

\section{Numerical Analysis}

In this section, we compute explicit numerical example to illustrate the analytical results. Assuming demand realizations at the two locations are independent and distributed normally, with mean 100 and standard deviation 50. Thus, $D_{i} \sim N(100,50)$. We truncate the distribution at 0 and redistribute this proportionally to the positive part of the distribution in order to rule out negative realizations of the demand variable. It should be noted that, this yields a slightly higher mean and slightly lower variance.

As provided in Table 3, the procurement cost, $w_{i}$ is assumed to be 20 per unit, the selling price $y_{i}$ is assumed to be twice as high as the procurement cost. Also, salvage value for each part is $25 \%$ of the product value, penalty for lost sales is zero and transshipment cost which is assumed to be equal for the two locations is 2 . It should be noted that, all the parameter values used in this analysis is assumed to be symmetric.

The optimal order quantities and average profits are illustrated in Figure 2 and Table 4.

Table 3. Assumed values for parameters used in numerical analysis.

\begin{tabular}{ccc}
\hline Cost parameter & Notation & Assumed values \\
\hline Procurement cost & $w_{i}, w_{j}$ & 20.00 \\
Selling price & $y_{i}, y_{j}$ & 40.00 \\
Salvage value & $s_{i}, s_{j}$ & 10.00 \\
Penalty cost & $p_{i}, p_{j}$ & 0 \\
Transshipment cost & $t_{i j}, t_{j i}$ & 2 \\
\hline
\end{tabular}

Source: Li Zou [29]. 
Table 4. Inventory decisions with $D_{i} \sim N(100,50)$.

\begin{tabular}{cccc}
\hline & & $\begin{array}{c}\text { Optimal } \\
\text { Inventory Q }\end{array}$ & $\begin{array}{c}\text { Average Profit at } \\
\text { each location, } e\end{array}$ \\
\hline $\begin{array}{c}\text { Without transshipment } \\
\text { With transshipments, thus }\end{array}$ & 12 & 122.5 & 1530 \\
$C_{i j}=C_{j i}$ & 18 & 107.0 & 1660 \\
& 20 & 112.3 & 1672 \\
& 22 & 114.1 & 1674 \\
$C_{i j}^{*}=C_{j i}^{*}$ & 23.3 & 115.9 & 1675 \\
& 26 & 117.1 & 1676 \\
& 35 & 119.4 & 1675 \\
& 40 & 127.0 & 1661 \\
& & 130.9 & 1648 \\
\hline
\end{tabular}

Source: Rudi, Kapur, and Pyke [30].

\section{Transshipment decisions with Optimal Inventory Quantity}

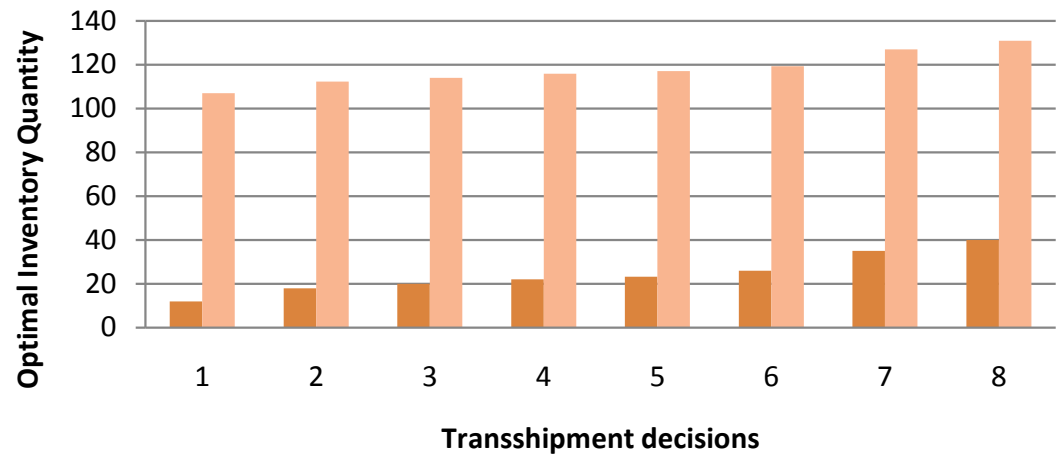

Figure 2. Transshipment decisions with Optimal Inventory Quantity.

As the numbers in Figure 2 and Table 4, transshipments improve profitability considerably over the case where transshipments are not permitted and we arrive at the highest increment in profitability when inventory orders are centrally coordinated as per this study. It could further be seen that, the equilibrium order quantity is increasing in the transshipment price, and there exist a coordinating transshipment price that decentralizes the joint-profit maximizing outcome. If the parent firm could however, impose a transshipment price of 23.3 , it would result in inventory orders that maximizes aggregate profits.

\section{Conclusion and Future Research}

In conclusion, this study analyses the role that transshipments play in modern inventory management and its benefits between two independent locations belonging to one parent firm. It is found in this study that, the use of an appropriate transshipment price is an effective tool for these locations to maximize their 
profits and optimize inventory level decisions. There exists a unique transshipment price that is optimal for both locations.

We show in the study how this also affects the optimal inventory orders at each location and found that, if each location aims to maximize its own profit, their inventory choices will not in general, maximize joint profits. In the case where inventory choice varies with transshipment prices, we find transshipment prices that induce the locations to choose inventory levels consistent with jointprofit maximization.

For future research, it is worthwhile to consider larger system consisting of more than two firms since our study only considered a two-location newsvendor problem with and without transshipments for a single replenishment period.

\section{References}

[1] Thomas, I., Abriatis, W. and Savage, C. (2013) Manufacturing and Trade: Inventories and Sales-December 2013. U.S. Department of Commerce.

[2] Wilson, R. (1934) A Scientific Routine for Stock Control. Harvard Business Review, 13, 116-128.

[3] Paterson, C., Kiesmuller, G., Teunter, R. and Clazebrook, K. (2011) Inventory Models with Lateral Transshipments: A Review. European Journal of Operational Research, 210, 125-136. https://doi.org/10.1016/j.ejor.2010.05.048

[4] Cohen, M., Cull, C., Lee, H. and Willen, D. (2000) Saturn's Supply-Chain Innovation: High Value in After-Sales Service. Sloan Management Review Summer, 2, 93 101.

[5] Aggarwal, S.P. (1967) Inventory Control Aspect in Warehouses. In: Symposium on Operations Research, Indian National Science Academy, New Delhi.

[6] Krishnan, K.S. and Rao, V.R.K. (1965) Inventory Control in N Warehouses. Journal of Industrial Engineering, 16, 212-215.

[7] Jonsson, H. and Silver, E.A. (1987) Analysis of a Two-Echelon Inventory Control System with Complete Redistribution. Management Science, 33, 215-227. https://doi.org/10.1287/mnsc.33.2.215

[8] Tagaras, G. (1989) Effects of Pooling on the Optimization and Service Levels of Two-Location Inventory Systems. IIE Transactions, 21, 250-257. https://doi.org/10.1080/07408178908966229

[9] Chase, R.B., Jacobs, F.R. and Aquilano, N.J. (2006) Operations Management for Competitive Advantage with Global Cases. McGraw-Hill/Irwin, Boston.

[10] Simchi-Levi, D., Kaminsky, P., and Simchi-Levi, E. (2008) Designing and Managing the Supply Chain: Concepts, Strategies and Case Studies. 3rd Edition, McGraw-Hill Irwin, Boston.

[11] Arrow, K.J., Harris, T. and Marschak, J. (1951) Optimal Inventory policy. Econometrica, 19, 250-272. https://doi.org/10.2307/1906813

[12] Coyle, J.J., Bardi, E.J. and Langley, C.J.J. (2003) The Management of Business Logistics: A Supply Chain Perspective. Thomson South Western, Mason.

[13] Dvoretzky, A., Kiefer, J. and Wolfowitz, J. (1952) The Inventory Problem: I. Case of Known Distributions of Demand. Econometrica, 20, 187-222. https://doi.org/10.2307/1907847

[14] Dvoretzky, A., Kiefer, J. and Wolfowitz, J. (1952) The Inventory Problem: II. Case of Unknown Distributions of Demand. Econometrica, 20, 450-466. 
https://doi.org/10.2307/1907414

[15] Chu, Y. and You, F. (2014) Simulation-Based Optimization for Multi-Echelon Inventory Systems under Uncertainty. Proceedings of the 2014 Winter Simulation Conference, Savannah, 7-10 December 2014, 385-394. https://doi.org/10.1109/WSC.2014.7019905

[16] Handfield, R., Warsing, D. and Wu, X. (2009) (Q, r) Inventory Policies in a Fuzzy Uncertain Supply Chain Environment. European Journal of Operational Research, 197, 609-619. https://doi.org/10.1016/j.ejor.2008.07.016

[17] Maiti, A., Maiti, M. and Maiti, M. (2009) Inventory Model with Stochastic Lead-Time and Price Dependent Demand Incorporating Advance Payment. Applied Mathematical Modeling, 33, 2433-2443. https://doi.org/10.1016/j.apm.2008.07.024

[18] Mandal, N.K., Roy, T.K. and Maiti, M. (2005) Multi-Objective Fuzzy Inventory Model with Three Constraints: A Geometric Programming Approach. Fuzzy Sets and Systems, 150, 87-106. https://doi.org/10.1016/j.fss.2004.07.020

[19] Ryu, S.W. and Lee, K.K. (2003) A Stochastic Inventory Model of Dual Sourced Supply Chain with Lead-Time Reduction. International Journal of Production Economics, 81-82, 513-524. https://doi.org/10.1016/S0925-5273(02)00294-3

[20] Solyali, O., Cordeau, J. and Laporte, G. (2012) Robust Inventory Routing under Demand Uncertainty. Transportation Science, 46, 327-340. https://doi.org/10.1287/trsc.1110.0387

[21] Robinson, L.W. (1990) Optimal and Approximate Policies in Multi-Period, Multilocation Inventory Models with Transshipments. Operations Research, 38, 278-295. https://doi.org/10.1287/opre.38.2.278

[22] Hu, X., Duenyas, I. and Kapuscinski, R. (2008) Optimal Joint Inventory and Transshipment under Uncertain Capacity. Operations Research, 56, 881-897. https://doi.org/10.1287/opre.1080.0515

[23] Zhao, H., Deshpande, V. and Ryan, J.K. (2008) Optimal Dynamic Production and Inventory Transshipment Policies for Multi-Location Make-to-Stock Systems. $O p$ erations Research, 56, 400-410. https://doi.org/10.1287/opre.1070.0494

[24] Heide, V.D. and Roodbergen, K.J. (2013) Transshipment and Rebalancing Policies for Library Books. European Journal of Operational Research, 22, 447-456. https://doi.org/10.1016/j.ejor.2013.02.008

[25] Yu, D.Z., Tang, S.Y. and Niederhoff, J. (2011) On the Benefits of Operational Flexibility in a Distribution Network with Transshipment. Omega, 39, 350-361. https://doi.org/10.1016/j.omega.2010.08.004

[26] Jiang, L. and Anupindi, R. (2010) Customer-Driven vs. Retailer-Driven Search: Channel Performance and Implications. Manufacturing and Service Operations Management, 12, 102-119. https://doi.org/10.1287/msom.1090.0258

[27] Zhao, X. and Atkins, D. (2009) Transshipment between Competing Retailers. IIE Transactions, 41, 665-676. https://doi.org/10.1080/07408170802702120

[28] Shen, W., Hu, X. and Liao, Y. (2014) Lateral Transshipment Strategy under Customer Request and Switching. Working Paper.

[29] Zou, L., Dresner, M. and Windle, R. (2010) A Two-Location Inventory Model with Transshipments in a Competitive Environment. International Journal of Production Economics, 125, 235-250. https://doi.org/10.1016/j.ijpe.2010.03.001

[30] Rudi, N., Kapur, S. and Pyke, D. (2001) A Two-Location Inventory Model with Transshipment and Localdecision Making. Management Science, 47, 1668-1680. https://doi.org/10.1287/mnsc.47.12.1668.10235 
Submit or recommend next manuscript to SCIRP and we will provide best service for you:

Accepting pre-submission inquiries through Email, Facebook, LinkedIn, Twitter, etc. A wide selection of journals (inclusive of 9 subjects, more than 200 journals)

Providing 24-hour high-quality service

User-friendly online submission system

Fair and swift peer-review system

Efficient typesetting and proofreading procedure

Display of the result of downloads and visits, as well as the number of cited articles Maximum dissemination of your research work

Submit your manuscript at: http://papersubmission.scirp.org/

Or contact ajibm@scirp.org 